\title{
Effects of Thromboxane Synthase Inhibition on Vascular Responsiveness in the In Vivo Rat Mesentery
}

\author{
Edwin K. Jackson \\ Division of Clinical Pharmacology, Department of Pharmacology, Vanderbilt University School of Medicine, Nashville, Tennessee 37232
}

\begin{abstract}
The purpose of this investigation was to determine the effects of thromboxane synthase inhibition on vascular responsiveness. To achieve this goal, the effects of thromboxane synthase inhibitors on mesenteric vascular responses to sympathetic nerve stimulation, norepinephrine, and angiotensin II were determined in vivo. In normotensive rats, chronic treatment with the thromboxane synthase inhibitor, UK38,485 $(100 \mathrm{mg} / \mathrm{kg} \cdot \mathrm{d} \times 7 \mathrm{~d})$, attenuated vascular responses to nerve stimulation and angiotensin II, but not to norepinephrine. Indomethacin treatment (5 $\mathrm{mg} / \mathrm{kg} \times$ three doses) did not attenuate vascular responses, but did prevent chronic UK38,485 administration from attenuating vascular reactivity. A single dose of $U K 38,485(100 \mathrm{mg} / \mathrm{kg})$ did not modify vascular responses to nerve stimulation or angiotensin II, even though platelet thromboxane synthase was inhibited completely. In spontaneously hypertensive rats, chronic administration (100 $\mathrm{mg} / \mathrm{kg} \cdot \mathrm{d} \times 7 \mathrm{~d})$ of either UK38,485, OKY1581, or U-63557A (three structurally distinct thromboxane synthase inhibitors) attenuated vascular responses to nerve stimulation and angiotensin II. Only $\mathrm{U}-63557 \mathrm{~A}$ suppressed responses to norepinephrine. Chronic treatment with UK38,485 or U-63557A did not influence vascular reactivity in hypertensive rats treated with indomethacin. Also, chronic administration of lower doses of UK38,485 or U-63557A (30 mg/kg $\cdot d \times 7$ d) did not affect vascular responsiveness in hypertensive rats, despite complete blockade of platelet thromboxane synthase. These data indicate that chronic administration of high doses of thromboxane synthase inhibitors attenuates vascular responses to sympathetic nerve stimulation and angiotensin II, but not usually to norepinephrine. This action may be mediated by endoperoxide shunting within the blood vessel wall.
\end{abstract}

\section{Introduction}

Norepinephrine (NE) ${ }^{1}$ and angiotensin II (AII) are well-known examples of vasoconstrictors that mobilize arachidonate from phospholipid stores (1-7) and, thereby, accelerate the rate of prostaglandin (PG) endoperoxide biosynthesis. PG endoperoxides are further processed via alternative metabolic pathways to either thromboxane $\mathrm{A}_{2}\left(\mathrm{TXA}_{2}\right), \mathrm{PGI}_{2}, \mathrm{PGE}_{2}, \mathrm{PGD}_{2}$, or $\mathrm{PGF}_{2 \alpha}$.

This work was presented in part to the 57th Scientific Session of the American Heart Association, Miami Beach, FL, 12-15 November 1984. Received for publication 24 June 1985.

1. Abbreviations used in this paper: AII, angiotensin II; NE, norepinephrine; PG, prostaglandin; PNS, periarterial nerve stimulation; $\mathrm{TXA}_{2}$, thromboxane.

J. Clin. Invest.

(C) The American Society for Clinical Investigation, Inc.

$0021-9738 / 85 / 12 / 2286 / 10 \$ 1.00$

Volume 76, December 1985, 2286-2295
Therefore, the profile of vasoconstrictor-induced prostanoid biosynthesis will depend upon the relative proximities and activities of the various enzymes catalyzing the transformation of PG endoperoxides.

One approach of altering the profile of vasoconstrictor-induced prostanoid biosynthesis would be to administer a $\mathrm{TXA}_{2}$ synthase inhibitor. By inactivating $\mathrm{TXA}_{2}$ synthase, PG endoperoxides that would have been transformed into $\mathrm{TXA}_{2}$ would now be available for $\mathrm{PGI}_{2}, \mathrm{PGD}_{2}, \mathrm{PGE}_{2}$, or $\mathrm{PGF}_{2 \alpha}$ biosynthesis. Evidence for "endoperoxide shunting" by $\mathrm{TXA}_{2}$ synthase inhibitors is abundant (8-12).

If $\mathrm{TXA}_{2}$ synthase inhibitors alter the profile of vasoconstrictor-induced prostanoid biosynthesis, this could modify the vascular response to vasoconstrictors and sympathetic nerve stimulation. $\mathrm{PGI}_{2}, \mathrm{PGD}_{2}$, and $\mathrm{PGE}_{2}$ attenuate the vascular response to vasoconstrictors and inhibit the release of NE from noradrenergic varicosities (13-18). In contrast, $\mathrm{TXA}_{2}$ may potentiate the vascular response to vasoconstrictors $(19,20)$. Therefore, a drug-induced shift from $\mathrm{TXA}_{2}$ synthesis and towards the synthesis of other prostanoids may attenuate the vascular response to vasoconstrictors and sympathetic nerve stimulation. The purpose of the present work is to test the hypothesis that inhibition of $\mathrm{TXA}_{2}$ synthase results in an attenuation of the vascular response to sympathetic nerve stimulation, NE, or AII.

\section{Methods}

As summarized in Table I, 11 separate protocols involving 142 animals were conducted over the course of $2 \mathrm{yr}$. In each protocol an equal number of rats (either six or seven) were randomly assigned to receive either a particular TXA $\mathrm{A}_{2}$ synthase inhibitor or the vehicle of that inhibitor (either olive oil or water). Thus, in each protocol a parallel group of control animals was randomized with the treatment group so that in no case was a historical control used for comparison. The protocols differed in five ways, i.e., type of TXA ${ }_{2}$ synthase inhibitor (either UK38,485, OKY 1581, or U-63557A), dose of TXA $A_{2}$ synthase inhibitor (either 30 or $100 \mathrm{mg} / \mathrm{kg}$ ), duration of treatment with a $\mathrm{TXA}_{2}$ synthase inhibitor (either single dose or daily doses over $7 \mathrm{~d}$ ), presence or absence of cyclooxygenase inhibition, and rat strain (either Sprague-Dawley or spontaneously hypertensive rats). UK38,485 was suspended in olive oil, whereas OKY 1581 and U-63557A were dissolved in water. All TXA synthase inhibitors and vehicles of $\mathrm{TXA}_{2}$ synthase inhibitors were administered by gavage between 8:00 and 9:00 a.m. Cyclooxygenase inhibition was achieved by administering subcutaneously $5 \mathrm{mg} / \mathrm{kg}$ of indomethacin suspended in olive oil 24,12 , and $2 \mathrm{~h}$ before assessment of vascular responsiveness. This dose of indomethacin was previously shown to block cyclooxygenase activity in the rat mesentery (21). In all protocols, vascular responsiveness was assessed $\sim 2 \mathrm{~h}$ after the last dose of the $\mathrm{TXA}_{2}$ synthase inhibitor or its vehicle.

Mesenteric vascular responsiveness was assessed using the in situ perfused mesentery technique previously described by Jackson and Campbell (22). Briefly, each animal was anesthetized with pentobarbital $(50 \mathrm{mg} / \mathrm{kg}$, i.p.), and a cannula was inserted into the abdominal aorta below the renal and mesenteric arteries. An extracorporeal shunt was established between the abdominal aorta and the superior mesenteric artery using a Harvard peristaltic pump (Harvard Apparatus Co., Inc., 


\begin{tabular}{|c|c|c|c|c|c|c|}
\hline Protocol no. & Group $(n)$ & Treatment & Dose & $\begin{array}{l}\text { Duration of } \\
\text { treatment }\end{array}$ & $\begin{array}{l}\text { Cyclooxygenase } \\
\text { inhibition }\end{array}$ & Rat strain \\
\hline & & & & $d$ & & \\
\hline \multirow[t]{2}{*}{1} & Experimental (6) & UK38,485 & $100 \mathrm{mg} / \mathrm{kg}$ & Single dose & No & SD \\
\hline & Control (6) & Olive oil & $1 \mathrm{ml} / \mathrm{kg}$ & Single dose & No & SD \\
\hline \multirow[t]{2}{*}{2} & Experimental (6) & UK38,485 & $100 \mathrm{mg} / \mathrm{kg}$ & Single dose & Yes & SD \\
\hline & Control (6) & Olive oil & $1 \mathrm{ml} / \mathrm{kg}$ & Single dose & Yes & SD \\
\hline \multirow[t]{2}{*}{3} & Experimental (6) & UK38,485 & $100 \mathrm{mg} / \mathrm{kg} \cdot \mathrm{d}$ & 7 & No & SD \\
\hline & Control (6) & Olive oil & $1 \mathrm{ml} / \mathrm{kg} \cdot \mathrm{d}$ & 7 & No & SD \\
\hline \multirow[t]{2}{*}{4} & Experimental (6) & UK 38,485 & $100 \mathrm{mg} / \mathrm{kg} \cdot \mathrm{d}$ & 7 & Yes & SD \\
\hline & Control (6) & Olive oil & $1 \mathrm{ml} / \mathrm{kg} \cdot \mathrm{d}$ & 7 & Yes & SD \\
\hline \multirow[t]{2}{*}{5} & Experimental (7) & UK 38,485 & $100 \mathrm{mg} / \mathrm{kg} \cdot \mathrm{d}$ & 7 & No & SHR \\
\hline & Control (7) & Olive oil & $1 \mathrm{ml} / \mathrm{kg} \cdot \mathrm{d}$ & 7 & No & SHR \\
\hline \multirow[t]{2}{*}{6} & Experimental (7) & UK 38,485 & $100 \mathrm{mg} / \mathrm{kg} \cdot \mathrm{d}$ & 7 & Yes & SHR \\
\hline & Control (7) & Olive oil & $1 \mathrm{ml} / \mathrm{kg} \cdot \mathrm{d}$ & 7 & Yes & SHR \\
\hline \multirow[t]{2}{*}{$7^{*}$} & Experimental (6) & UK 38,485 & $30 \mathrm{mg} / \mathrm{kg} \cdot \mathrm{d}$ & 7 & No & SHR \\
\hline & Control (6) & Olive oil & $1 \mathrm{ml} / \mathrm{kg} \cdot \mathrm{d}$ & 7 & No & SHR \\
\hline \multirow[t]{2}{*}{8} & Experimental (7) & OK 1581 & $100 \mathrm{mg} / \mathrm{kg} \cdot \mathrm{d}$ & 7 & No & SHR \\
\hline & Control (7) & Water & $1 \mathrm{ml} / \mathrm{kg} \cdot \mathrm{d}$ & 7 & No & SHR \\
\hline \multirow[t]{2}{*}{9} & Experimental (7) & U-63557A & $100 \mathrm{mg} / \mathrm{kg} \cdot \mathrm{d}$ & 7 & No & SHR \\
\hline & Control (7) & Water & $1 \mathrm{ml} / \mathrm{kg} \cdot \mathrm{d}$ & 7 & No & SHR \\
\hline \multirow[t]{2}{*}{10} & Experimental (7) & U-63557A & $100 \mathrm{mg} / \mathrm{kg} \cdot \mathrm{d}$ & 7 & Yes & SHR \\
\hline & Control (7) & Water & $1 \mathrm{ml} / \mathrm{kg} \cdot \mathrm{d}$ & 7 & Yes & SHR \\
\hline \multirow[t]{2}{*}{$11^{*}$} & Experimental (6) & U-63557A & $30 \mathrm{mg} / \mathrm{kg} \cdot \mathrm{d}$ & 7 & No & SHR \\
\hline & Control (6) & Water & $1 \mathrm{ml} / \mathrm{kg} \cdot \mathrm{d}$ & 7 & No & SHR \\
\hline
\end{tabular}

Cyclooxygenase inhibition was achieved with $5 \mathrm{mg} / \mathrm{kg}$ of indomethacin administered subcutaneously 24,12 , and $2 \mathrm{~h}$ before measurement of vascular responsiveness. Volume of vehicle given to experimental and control groups was the same. TXA administered by gavage. SD, Sprague-Dawley; SHR, spontaneously hypertensive rat. * Effects on AII response not tested.

Natick, MA) to maintain blood flow at a constant rate $(3 \mathrm{ml} / \mathrm{min})$. Both mesenteric perfusion pressure and mean arterial blood pressure were monitored with pressure transducers (Narco Biosystems, Houston, TX, model RP 1500) and were recorded on a Grass model 79 polygraph (Grass Instrument Co., Quincy, MA). In that blood flow was held constant, changes in mesenteric vascular resistance induced a proportional change in mesenteric perfusion pressure. After all surgical procedures were completed, the animals were allowed to stabilize for $\mathbf{4 0} \mathrm{min}$, during which time supplemental intravenous (juglar vein) boluses of pentobarbital $(1.5 \mathrm{mg} / \mathrm{kg})$ were administered as needed. No additional anesthetic was administered once the experimental period was begun.

In each animal, vasoconstrictor responses to sympathetic nerve stimulation were elicited at 3-min intervals by electrically stimulating the mesenteric sympathetic nerves with a bipolar platinum electrode positioned around the superior mesenteric artery. Changes in mesenteric perfusion pressure (i.e., vasoconstrictor responses) to periarterial nerve stimulation (PNS) were elicited with a 20-s train of 34-V biphasic pulses $1 \mathrm{~ms}$ in duration at 3,5 , or $7 \mathrm{~Hz}$. In a previous study, it was demonstrated that PNS in this preparation induces vasoconstriction by activating the release of neuronal NE (22). After responses to PNS were obtained, responses to exogenous NE were elicited at 3-min intervals by injecting either 100,200 , or $300 \mathrm{ng}$ of $\mathrm{NE}$ (as free base) into the superior mesenteric artery. In all experiments $\mathrm{NE}$ injections were performed subsequent to the nerve stimulation period. This was done to avoid any residual effects that NE injections might have on responses to PNS owing to activation of prejunctional $\alpha$-adrenoceptors. In this preparation the vascular effects of both endogenously released and exogenously administered NE are due to activation of postjunctional $\alpha_{1}$-adrenoceptors (23). Finally, an intramesenteric artery infusion of AII was begun at a rate of $9 \mathrm{ng} / \mathrm{min}$ and sustained for $10 \mathrm{~min}$.

The effects of each $\mathrm{TXA}_{2}$ synthase inhibitor on vasoconstrictor responses to PNS and exogenous NE were determined by comparing the vasoconstrictor responses in the vehicle controls to the responses in the treated animals using a two-factor analysis of variance. In this analysis frequency of PNS or dose of NE was one fixed factor (three levels) and treatment was the second fixed factor (two levels). Similarly, the effect of an inhibitor on vasoconstrictor responses to AII were determined by two-factor analysis of variance. In this case, time (10 levels) was one fixed factor and treatment (two levels) was the second fixed factor. All analyses were performed on the Vanderbilt Digital Equipment Corporation (Maynard, MA) 1099 computer using the Statistical Package for the Social Sciences. An inhibitor was considered to alter vasoconstrictor responses if the treatment factor in the analysis afforded a $P$ value of $<0.05$. All values given in figures indicate mean \pm standard error of the mean.

To determine the acute effects of UK38,485, OKY1581, and U63557A on platelet $\mathrm{TXA}_{2}$ synthase activity, spontaneously hypertensive rats were anesthetized with pentobarbital $(50 \mathrm{mg} / \mathrm{kg}$, i.p.) and a silastic cannula was inserted into the left carotid artery. $24 \mathrm{~h}$ later each rat was treated by gavage with either $30 \mathrm{mg} / \mathrm{kg}$ or $100 \mathrm{mg} / \mathrm{kg}$ of either U-63557A, 

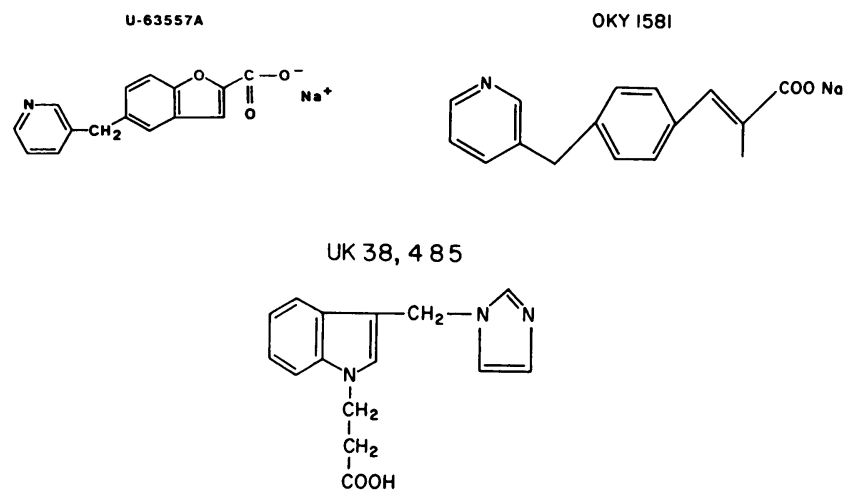

Figure 1. The chemical structures of U-63557A, OKY1581, and UK 38,485 .

OKY 1581 , or UK 38,485 . Blood samples $(0.6 \mathrm{ml})$ were removed via the carotid cannula just before and 3,10 , and $24 \mathrm{~h}$ after drug administration. The blood samples were placed in $12 \times 75-\mathrm{mm}$ borosilicate glass tubes and were clotted for $1 \mathrm{~h}$ in a water bath maintained at $37^{\circ} \mathrm{C}$. Next, the samples were placed on ice and centrifuged at $4^{\circ} \mathrm{C}$ and the serum frozen at $-20^{\circ} \mathrm{C}$ and later assayed for $\mathrm{TXB}_{2}$. Serum $\mathrm{TXB}_{2}$ was measured by radioimmunoassay. Briefly, $200 \mu \mathrm{l}$ of diluted sample was incubated for $20 \mathrm{~h}$ at $4^{\circ} \mathrm{C}$ with $100 \mu \mathrm{l}$ of antiserum (antibody dilution $=1: 32,000$ ) and $100 \mu \mathrm{l}$ of ${ }^{125} \mathrm{I}$-labeled $\mathrm{TxB}_{2}$-histamine $(1,500 \mathrm{cpm})$. The assay buffer was a $0.1 \mathrm{M}$ phosphate solution ( $\mathrm{pH} 7$ ) containing $0.1 \%$ bovine albumin, $0.5 \%$ bovine gammaglobulin, and $1 \mathrm{mM}$ sodium azide. After incubation, $600 \mu \mathrm{l}$ of $21 \%$ polyethylene glycol (PEG) 6000 was added to each tube and bound counts separated by centrifugation at $4,000 \mathrm{rpm}$ for $15 \mathrm{~min}$ at $4^{\circ} \mathrm{C}$. The assay sensitivity was $3.9 \mathrm{pg}$ with $50 \%$ displacement at 22 pg. Details on the development of this assay, antibody cross-reactivity, and assay conditions have been published previously (24). TXB ${ }_{2}$ levels in serum from clotted blood reflect platelet $\mathrm{TXA}_{2}$ synthase activity (2527) at the ambient plasma levels of the inhibitor.

Further experiments were performed to determine whether or not the degree of platelet $\mathrm{TXA}_{2}$ synthase inhibition was the same $2 \mathrm{~h}$ after a single dose of UK 38,485 vs. $2 \mathrm{~h}$ after the last dose of a week-long pretreatment with UK38,485. In these experiments Sprogue-Dawley rats were given either $100 \mathrm{mg} / \mathrm{kg}$ of UK38,485 or olive oil $(1 \mathrm{ml} / \mathrm{kg})$ by gavage. Some animals had been pretreated for $7 \mathrm{~d}$ with daily doses of UK $38,485(100 \mathrm{mg} / \mathrm{kg})$ or olive oil, whereas others had not been pretreated. $2 \mathrm{~h}$ later, the rats were decapitated and blood samples collected. $\mathrm{TXB}_{2}$ levels were determined in sera from these samples as described above.
UK38,485, OKY 1581, and U-63557A were obtained from Pfizer Central Research (Sandwich, Kent, England), Ono Pharmaceutical Company, Ltd. (Osaka, Japan), and the Upjohn Company (Kalamazoo, MI), respectively. Indomethacin and NE bitartrate were from Sigma Chemical Company (St. Louis, MO). AII was obtained from Peninsula Laboratories (Belmont, CA). NE (dissolved in saline) and AII (dissolved in a glycine buffer, $\mathrm{pH} 7.4$, containing bovine serum albumin and $\mathrm{NaCl}$ ) were prepared in advance and stored at $-70^{\circ} \mathrm{C}$ in aliquots of sufficient size for one experiment.

Adult (15-18 wk old) male spontaneously hypertensive rats of the Okamoto-Aoki strain (Taconic Farms, Inc., Germantown, NY) and Sprague-Dawley rats (Sasco Inc., Omaha, NB) were housed four to a cage in an animal facility providing a constant temperature of $22^{\circ} \mathrm{C}$. Room lights were automatically controlled to provide illumination from 6:00 a.m. to 6:00 p.m. daily. All rats were fed a diet of Wayne Lab-Blox (Allied Mills, Inc., Memphis, TN) containing $170 \mathrm{meq} / \mathrm{kg}$ and $246 \mathrm{meq} /$ $\mathrm{kg}$ of sodium and potassium, respectively, and tap water ad libitum. All animals were allowed at least $1 \mathrm{wk}$ of acclimatization following arrival to the animal facility.

\section{Results}

Fig. 1 depicts the chemical structures of UK38,485, OKY 1581 , and U-63557A. As indicated all three compounds are structurally distinct. UK 38,485 is a derivative of imidazole, whereas OKY 1581 and U-63557A are pyridine derivatives. As illustrated in Fig. 2 UK38,485, OKY1581, and U-63557A suppressed the production of $\mathrm{TXB}_{2}$ by platelets ex vivo after oral administration of either $30 \mathrm{mg} / \mathrm{kg}$ or $100 \mathrm{mg} / \mathrm{kg}$. Although $30 \mathrm{mg} / \mathrm{kg}$ afforded nearly complete blockade of $\mathrm{TXB}_{2}$ biosynthesis for up to $3 \mathrm{~h}$ after administration, some recovery was noted during the ensuing $21 \mathrm{~h}$. However, $100 \mathrm{mg} / \mathrm{kg}$ of all three inhibitors abolished platelet $\mathrm{TXB}_{2}$ production for at least $24 \mathrm{~h}$. Fig. 3 demonstrates that $100 \mathrm{mg} / \mathrm{kg}$ of UK 38,485 caused nearly complete abolition of platelet $\mathrm{TXA}_{2}$ synthase $2 \mathrm{~h}$ after administration, regardless of whether or not animals were given a single dose (left panel) or were pretreated with $100 \mathrm{mg} / \mathrm{kg} \cdot \mathrm{d}$ of UK38,485 for $7 \mathrm{~d}$ (right panel).

Protocols 1 and 2. In normotensive rats, a single dose of UK $38,485(100 \mathrm{mg} / \mathrm{kg})$ significantly suppressed vascular responsiveness to exogenous NE (Fig. 4, right panel) but did not alter the vascular response to AII (Fig. 5). Although the response to PNS tended to be suppressed, this suppression did not achieve
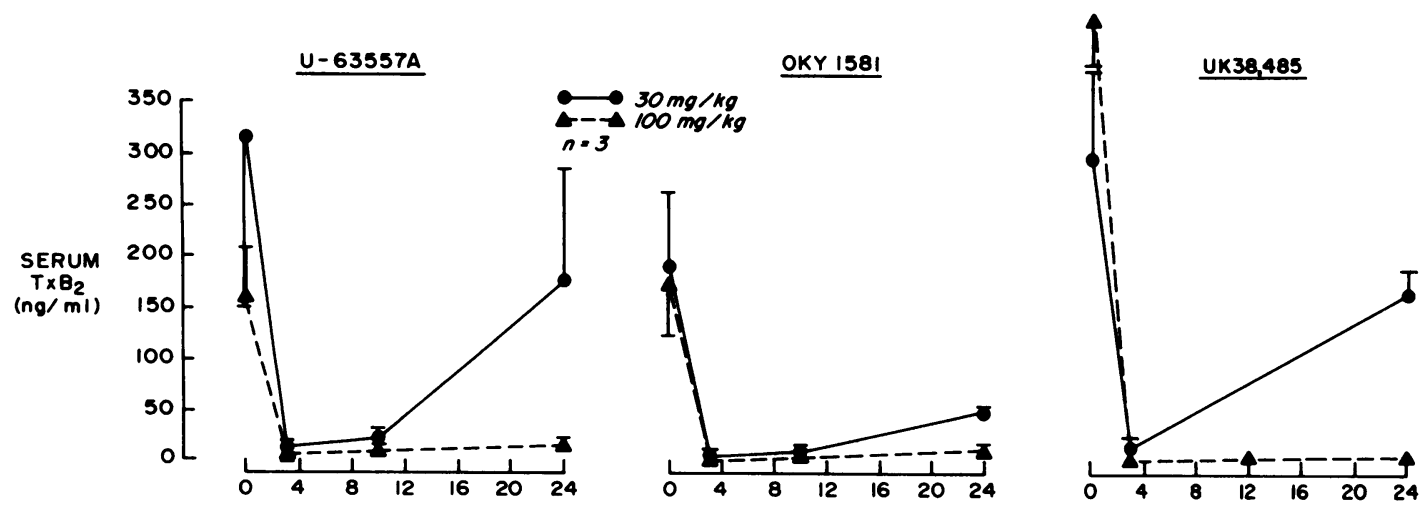

TIME (Hours)

Figure 2. Suppression of ex vivo platelet $\mathrm{TXB}_{2}$ generation by orally administered U-63557A, OKY 1581, and UK38,485 in spontaneously hypertensive rats. All points are significantly different $(P<0.05)$ from base line for all three drugs at both doses (Dunnett's test), except for the 24-h point with $30 \mathrm{mg} / \mathrm{kg}$ of U-63557A. 


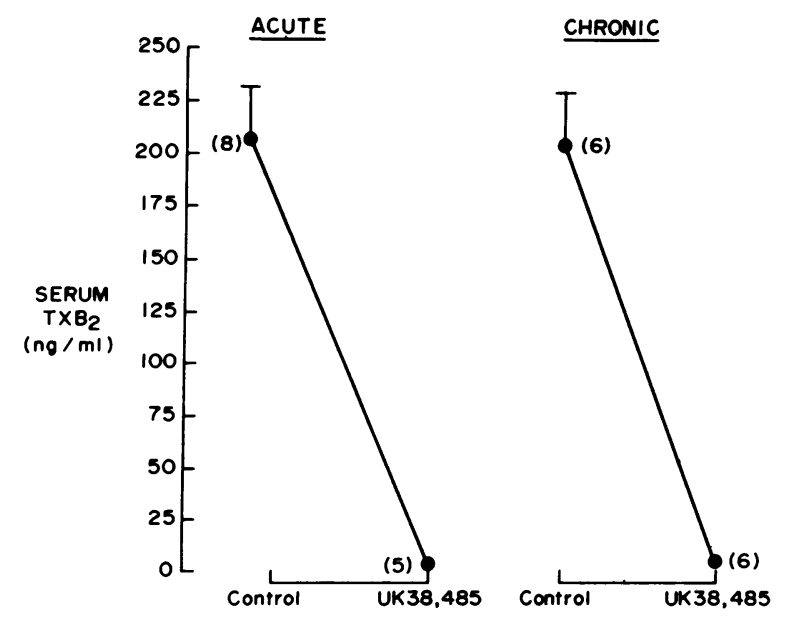

Figure 3. Suppression of ex vivo platelet $\mathrm{TXB}_{2}$ generation by UK38,485 $(100 \mathrm{mg} / \mathrm{kg}) 2 \mathrm{~h}$ after a single oral dose (acute) or $2 \mathrm{~h}$ after the last oral dose of a 7-d regimen (chronic) in Sprague-Dawley rats. After acute and chronic UK38,485 treatment, the serum $\mathrm{TXB}_{2}$ levels were $3 \pm 1$ and $6 \pm 1 \mathrm{ng} / \mathrm{ml}$, respectively.

statistical significance (Fig. 4, left panel). In normotensive rats pretreated with indomethacin, a single dose of UK38,485 (100 $\mathrm{mg} / \mathrm{kg}$ ) no longer inhibited the vascular responsiveness to exogenous NE (Fig. 6, right panel) and, as in nonindomethacinpretreated animals, did not influence the response to PNS (Fig. 6, left panel) or AII (Fig. 7).

Protocols 3 and 4. Even though platelet $\mathrm{TXA}_{2}$ synthase activity was suppressed equivalently $2 \mathrm{~h}$ after a single $100 \mathrm{mg} / \mathrm{kg}$ dose of UK 38,485 compared to $2 \mathrm{~h}$ after the last dose of a weeklong pretreatment, the effects of chronic UK38,485 treatment on vascular responsiveness were markedly different from the effects of acute administration of UK38,485. As shown in Fig. 8 , chronic treatment with UK $38,485(100 \mathrm{mg} / \mathrm{kg} \cdot \mathrm{d} \times 7 \mathrm{~d}) \mathrm{sig}-$ nificantly inhibited the vascular response to PNS (left panel), but did not alter the vascular response to exogenous NE (right panel). Also in contrast to the effects of a single $100 \mathrm{mg} / \mathrm{kg}$ dose of UK 38,485 , chronic treatment with UK38,485 attenuated the vascular response to AII (Fig. 9). Figs. 10 and 11 demonstrate that pretreatment with indomethacin abolishes the effects of chronic UK 38,485 administration on vascular responsiveness
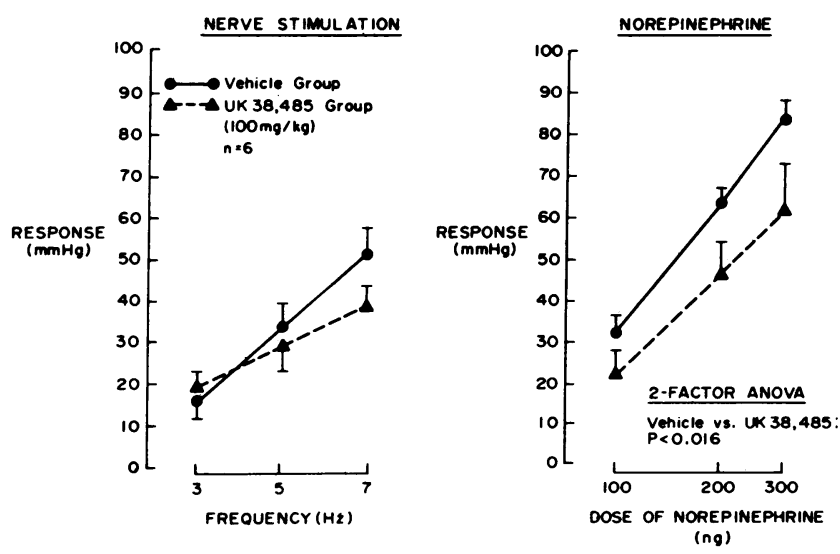

Figure 4. Effects of a single dose of UK38,485 $(100 \mathrm{mg} / \mathrm{kg})$ on vascular responses to PNS (left panel) or exogenous NE (right panel) in Sprague-Dawley rats.

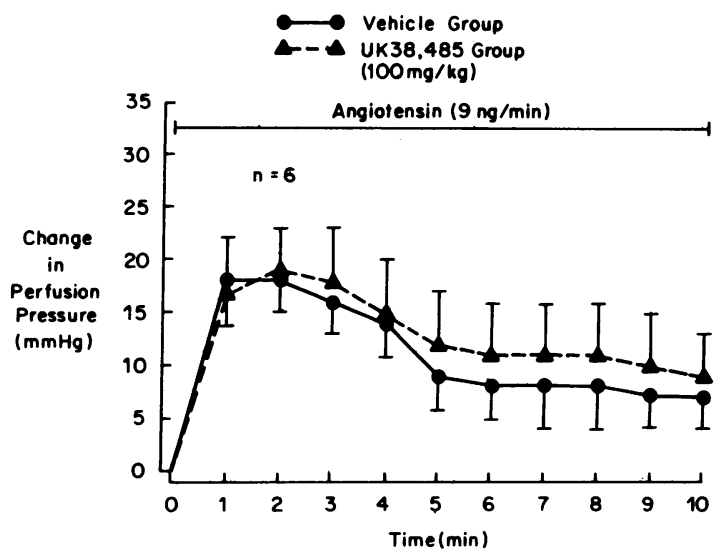

Figure 5. Effects of a single oral dose of UK38,485 $(100 \mathrm{mg} / \mathrm{kg})$ on vascular responsiveness to AII in Sprague-Dawley rats.

to PNS (Fig. 10) and AII (Fig. 11). When all normotensive control rats receiving indomethacin were compared with all normotensive control rats not receiving indomethacin, indomethacin was found not to depress the vascular responses to PNS, exogenous NE, or AII (data from Figs. 4-11).

Protocols 5, 6, and 7. Figs. 12 and 13 illustrate the effects of chronic treatment with UK $38,485(100 \mathrm{mg} / \mathrm{kg} \cdot \mathrm{d} \times 7 \mathrm{~d})$ on vascular responsiveness in the hypertensive rat. As in the normotensive rat, UK 38,485 significantly suppressed the response to PNS (Fig. 12, left panel) and AII (Fig. 13), but did not alter the response to exogenous NE (Fig. 12, right panel). As shown in Figs. 14 and 15 , in indomethacin-pretreated hypertensive rats, chronic administration of UK $38,485(100 \mathrm{mg} / \mathrm{kg} \cdot \mathrm{d} \times 7 \mathrm{~d}) \mathrm{no}$ longer suppressed vascular responsiveness to either PNS (Fig. 14, left panel) or AII (Fig. 15). Although platelet TXA synthase activity was similarly abolished $3 \mathrm{~h}$ after a dose of either 30 or $100 \mathrm{mg} / \mathrm{kg}$ of UK 38,485 (Fig. 2), chronic (7 d) treatment with $30 \mathrm{mg} / \mathrm{kg} \cdot \mathrm{d}$ of $\mathrm{UK} 38,485$ did not influence vascular responsiveness in hypertensive rats (Fig. 16).

Protocol 8. The effects of chronic treatment with OKY 1581 $(100 \mathrm{mg} / \mathrm{kg} \cdot \mathrm{d} \times 7 \mathrm{~d})$ were exactly like those observed after chronic UK38,485 administration. Like UK38,485, in hypertensive rats $\mathrm{OKY} 1581$ significantly inhibited the responses to
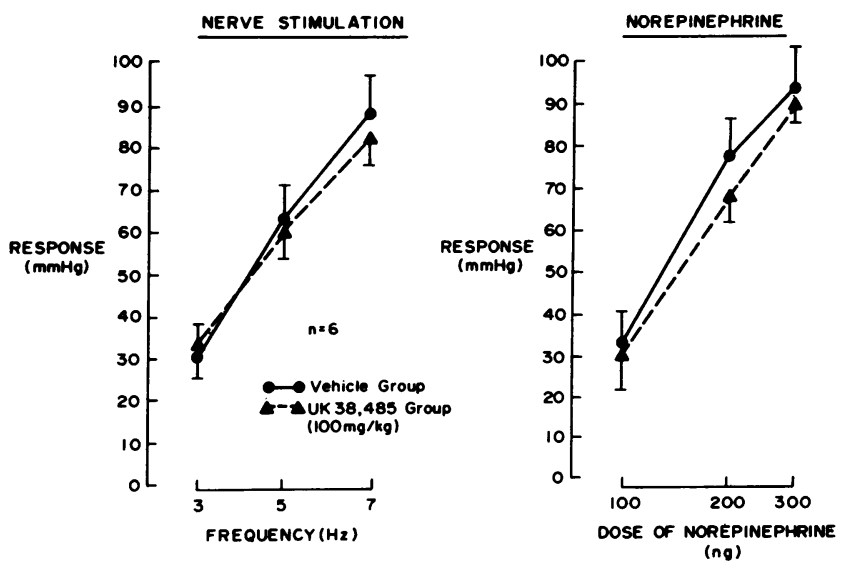

Figure 6. Effects of a single oral dose of UK38,485 $(100 \mathrm{mg} / \mathrm{kg})$ on vascular responses to PNS (left panel) and exogenous NE (right panel) in Sprague-Dawley rats pretreated with indomethacin $(5 \mathrm{mg} / \mathrm{kg} \times$ three doses, subcutaneously). 


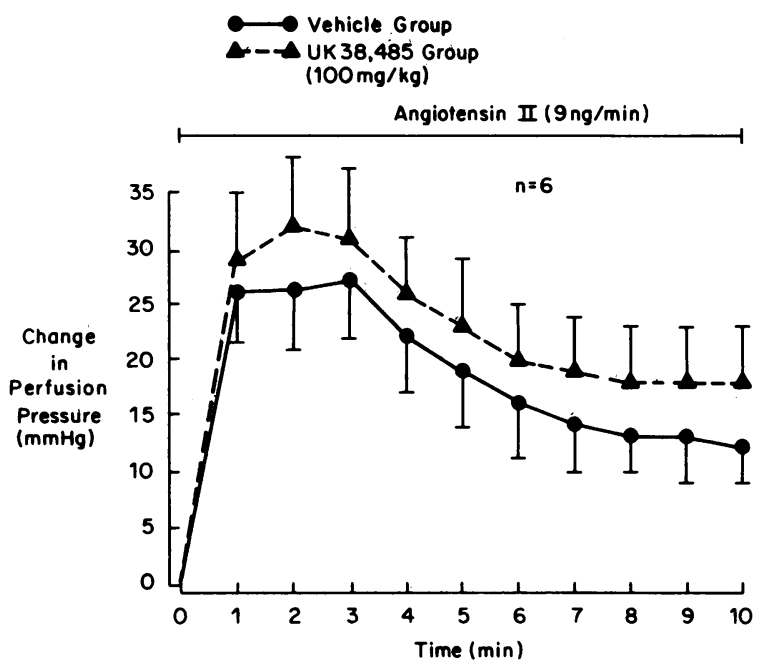

Figure 7. Effects of a single oral dose of UK $38,485(100 \mathrm{mg} / \mathrm{kg})$ on vascular responsiveness to AII in Sprague-Dawley rats pretreated with indomethacin $(5 \mathrm{mg} / \mathrm{kg} \times$ three doses, subcutaneously).

PNS (Fig. 17, left panel) and AII (Fig. 18), but did not alter the vascular response to exogenous NE (Fig. 17, right panel).

Protocols 9, 10, and 11. The effects of a third TXA 2 synthase inhibitor, U-63557A, on vascular responsiveness in the hypertensive rat also were examined. Chronic administration of U$63557 \mathrm{~A}(100 \mathrm{mg} / \mathrm{kg} \cdot \mathrm{d} \times 7 \mathrm{~d})$ markedly suppressed the vascular response to PNS (Fig. 19, left panel), exogenous NE (Fig. 19, right panel), and AII (Fig. 20). However, vascular responses to PNS were suppressed to a greater extent by U-63557A than were responses to NE. Also U-63557A suppressed the vascular response to PNS more than did either UK38,485 or OKY1581. For example, in hypertensive rats chronic treatment with UK $38,485(100 \mathrm{mg} / \mathrm{kg} \cdot \mathrm{d} \times 7 \mathrm{~d})$ reduced the mean vascular response to PNS by 4,11 , and $17 \mathrm{mmHg}$ at 3,5 , and $7 \mathrm{~Hz}$, respectively, which was comparable to the 6,11 , and $17 \mathrm{mmHg}$ reduction at 3,5 , and $7 \mathrm{~Hz}$, respectively, obtained with OKY 1581 $(100 \mathrm{mg} / \mathrm{kg} \cdot \mathrm{d} \times 7 \mathrm{~d})$ in hypertensive rats. On the other hand, U-63557A reduced the mean vascular response to PNS by 10 , 19 , and $30 \mathrm{~mm} \mathrm{Hg}$ at 3,5 , and $7 \mathrm{~Hz}$, respectively. When compared using a fixed model two-factor analysis of variance without
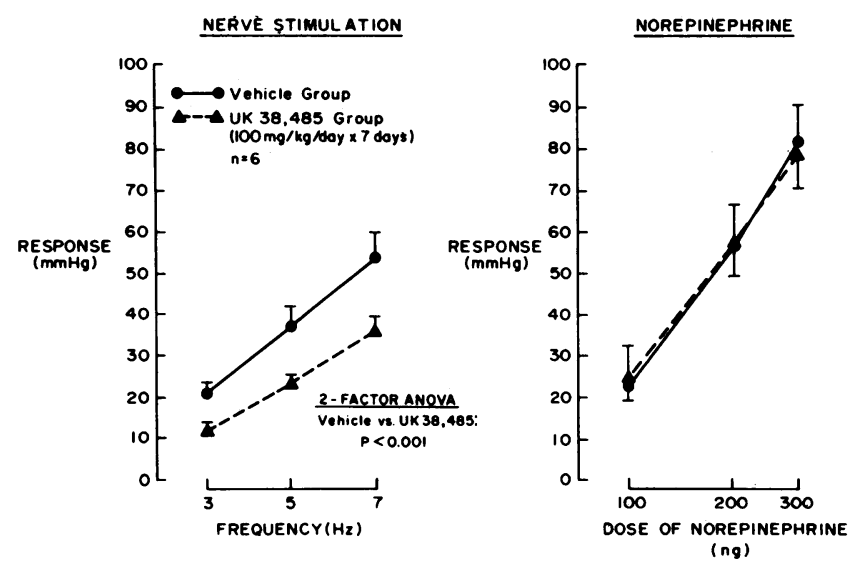

Figure 8. Effects of chronic oral treatment with UK38,485 (100 mg/ $\mathrm{kg} \cdot \mathrm{d} \times 7 \mathrm{~d}$ ) on vascular responses to PNS (left panel) and exogenous $\mathrm{NE}$ (right panel) in Sprague-Dawley rats.

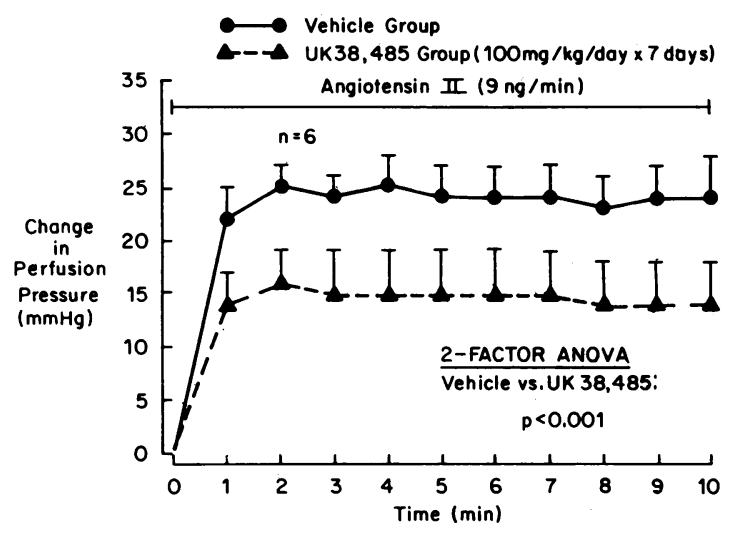

Figure 9. Effects of chronic oral treatment with UK38,485 (100 mg/ $\mathrm{kg} \cdot \mathrm{d} \times 7 \mathrm{~d}$ ) on vascular responsiveness to AIl in Sprague-Dawley rats.

replication, the reduction in the mean response to PNS by U63557A was significantly $(P<0.05)$ greater than the reduction achieved with either UK 38,485 or OKY 1581 .

The effect of chronic U-63557A administration $(100 \mathrm{mg} /$ $\mathrm{kg} \cdot \mathrm{d} \times 7 \mathrm{~d}$ ) on vascular responsiveness in indomethacin-pretreated hypertensive rats also was investigated. In indomethacinpretreated animals U-63557A did not significantly suppress vascular responses to either PNS (Fig. 21, left panel), exogenous NE (Fig. 21, right panel), or AII (Fig. 22). When all hypertensive control rats receiving indomethacin were compared to all hypertensive control rats not receiving indomethacin, indomethacin was found not to depress the vascular response to PNS, exogenous NE, or AII (data from Figs. 12-23). Like UK38,485, lower chronic doses of U-63557A ( $30 \mathrm{mg} / \mathrm{kg} \cdot \mathrm{d} \times 7 \mathrm{~d})$ did not influence vascular responsiveness (Fig. 23). This occurred despite the fact that 30 and $100 \mathrm{mg} / \mathrm{kg}$ doses of U-63557A produced equivalent inhibition of platelet $\mathrm{TXA}_{2}$ synthase activity during the first $3 \mathrm{~h}$ after administration (Fig. 2).

Base-line Perfusion Pressure and Mean Arterial Blood Pressure. Table II lists the mesenteric perfusion pressure and mean arterial blood pressure for each group. In no instances did a $\mathrm{TXA}_{2}$ synthase inhibitor alter base-line mesenteric perfusion pressure. Similarly, mean arterial blood pressure was not altered, except by UK38,485 in hypertensive rats (protocol 5).

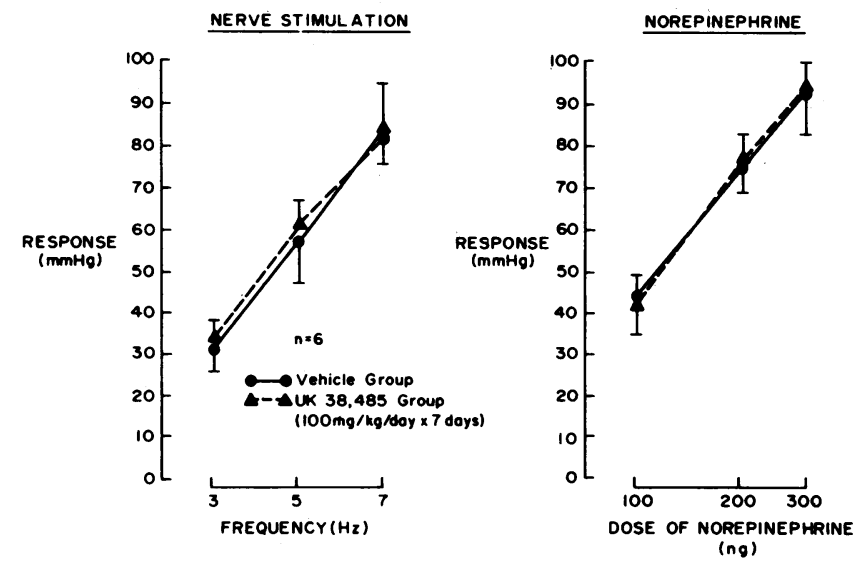

Figure 10. Effects of chronic oral treatment with UK $38,485(100 \mathrm{mg} /$ $\mathrm{kg} \cdot \mathrm{d} \times 7 \mathrm{~d}$ ) on vascular responses to PNS (left panel) and exogenous $\mathrm{NE}$ (right panel) in Sprague-Dawley rats pretreated with indomethacin $(5 \mathrm{mg} / \mathrm{kg} \times$ three doses, subcutaneously). 


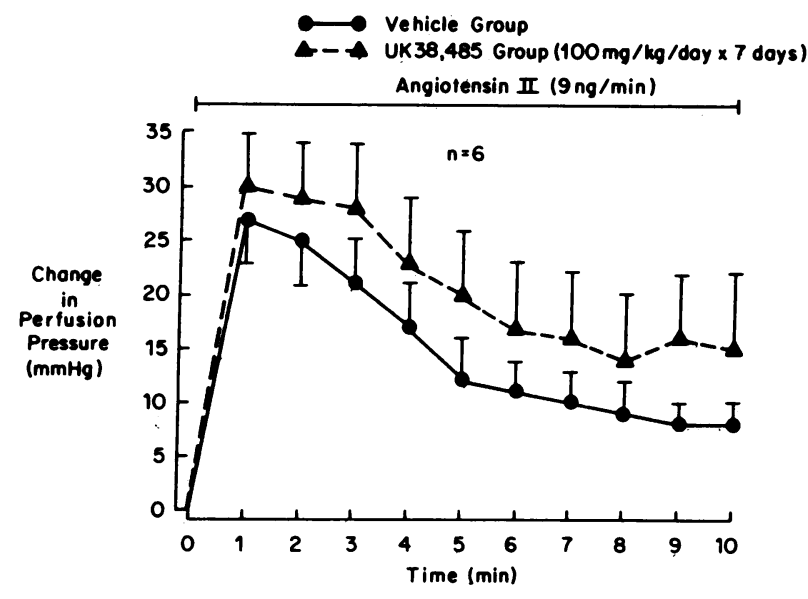

Figure 11. Effects of chronic oral treatment with UK38,485 (100 mg/ $\mathrm{kg} \cdot \mathrm{d} \times 7 \mathrm{~d})$ on vascular responsiveness to AII in Sprague-Dawley rats pretreated with indomethacin $(5 \mathrm{mg} / \mathrm{kg} \times$ three doses, subcutaneously).

\section{Discussion}

The purpose of these experiments was to test the hypothesis that inhibition of $\mathrm{TXA}_{2}$ synthase can attenuate the vascular response to AII, sympathetic nerve stimulation, and/or norepinephrine. Vasoconstrictor hormones, such as AII and NE, increase the release of arachidonate from tissue stores, perhaps by activating specific $\mathrm{Ca}^{++}$-calmodulin-dependent phospholipases (28). Once mobilized, arachidonate can be transformed by cyclooxygenase into $\mathrm{PGH}_{2} ; \mathrm{PGH}_{2}$ then serves as a common precursor for a diverse group of prostanoids including $\mathrm{TXA}_{2}, \mathrm{PGI}_{2}, \mathrm{PGE}_{2}$, and $\mathrm{PGD}_{2}$. TXA $\mathrm{A}_{2}$ synthase inhibitors block the conversion of $\mathrm{PGH}_{2}$ to $\mathrm{TXA}_{2}$, thereby decreasing $\mathrm{TXA}_{2}$ production and increasing the amount of $\mathrm{PGH}_{2}$ available for alternative metabolic routes. Therefore, selective $\mathrm{TXA}_{2}$ synthase inhibitors should decrease hormone-induced $\mathrm{TXA}_{2}$ synthesis while enhancing hormoneinduced synthesis of other prostanoids. Indeed, in vitro and in vivo evidence for "endoperoxide shunting" after administration of TXA 2 synthase inhibitors is abundant (8-12). Because TXA potentiates the vascular response to vasoconstrictors $(19,20)$, whereas $\mathrm{PGE}_{2}, \mathrm{PGD}_{2}$, and $\mathrm{PGI}_{2}$ attenuate the action of vasoconstrictors and reduce the release of $\mathrm{NE}$ from sympathetic nerve
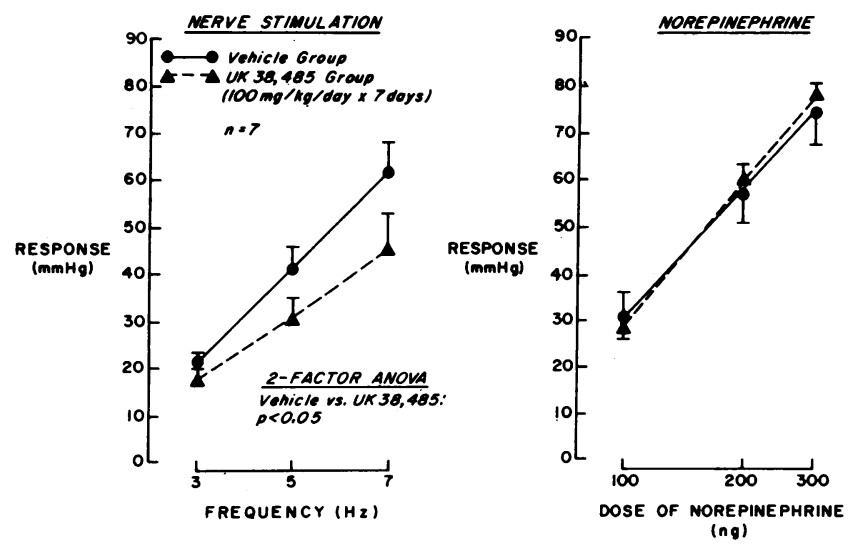

Figure 12. Effects of chronic oral treatment with UK $38,485(100 \mathrm{mg} /$ $\mathrm{kg} \cdot \mathrm{d} \times 7 \mathrm{~d}$ ) on vascular responses to PNS (left panel) and exogenous NE (right panel) in spontaneously hypertensive rats.

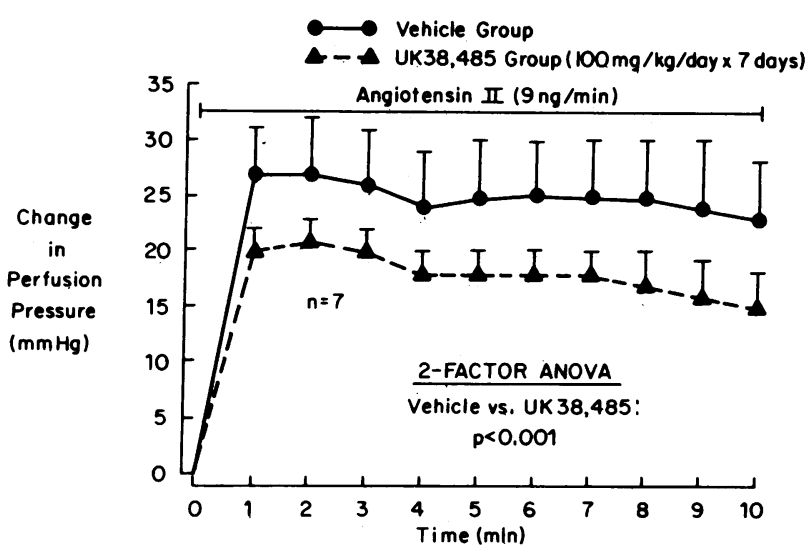

Figure 13. Effects of chronic oral treatment with UK38,485 (100 mg/ $\mathrm{kg} \cdot \mathrm{d} \times 7 \mathrm{~d}$ ) on vascular responsiveness to AII in spontaneously hypertensive rats.

terminals (13-18), TXA $\mathrm{A}_{2}$ synthase inhibitors should attenuate the vascular response to AII, sympathetic nerve stimulation, and/ or NE.

The vascular response to AII was reduced by chronic administration of UK38,485, OKY 1581, and U-63557A. All three inhibitors attenuated the vascular response to AII by a similar amount, indicating that the observed effect was due specifically to inhibition of $\mathrm{TXA}_{2}$ synthase and not a result of some unknown nonspecific action of any one inhibitor. Unlike $\mathrm{TXA}_{2}$ synthase inhibition, cyclooxygenase inhibition did not attenuate the vascular response to AII. However, in animals pretreated with indomethacin, $\mathrm{TXA}_{2}$ synthase inhibition failed to attenuate AII responses. This was confirmed in three separate experiments. These observations suggest that the attenuation of vascular responses to AII by $\mathrm{TXA}_{2}$ synthase inhibition is due primarily to either enhanced prostaglandin biosynthesis per se, presumably due to endoperoxide shunting, or to enhanced prostaglandin production in combination with a reduction in $\mathrm{TXA}_{2}$ levels.

A critical issue raised by these observations relates to the site of the putative endoperoxide shunting responsible for attenuating vascular responses to AII. Platelets are a rich source of $\mathrm{TXA}_{2}$ synthase (29), and platelet-endothelial interactions would pro-
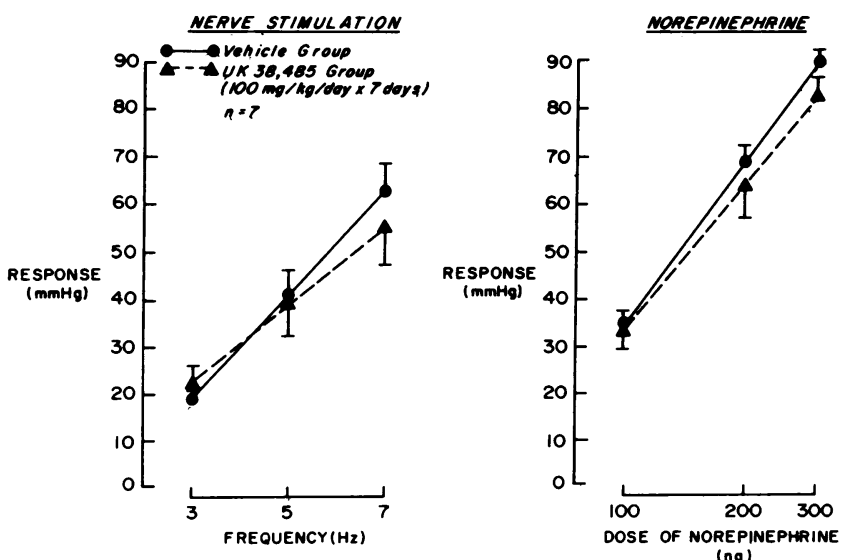

Figure 14. Effects of chronic oral treatment with UK38,485 $(100 \mathrm{mg} /$ $\mathrm{kg} \cdot \mathrm{d} \times 7 \mathrm{~d}$ ) on vascular response to PNS (left panel) and exogenous NE (right panel) in spontaneously hypertensive rats pretreated with indomethacin $(5 \mathrm{mg} / \mathrm{kg} \times$ three doses, subcutaneously). 


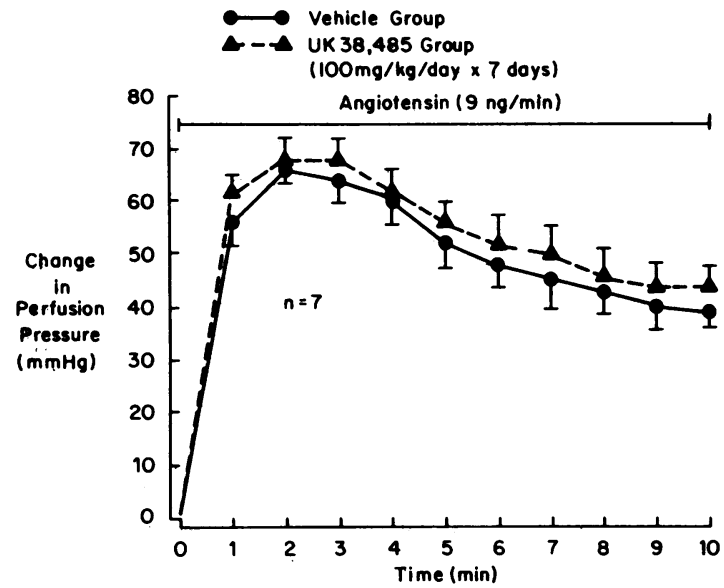

Figure 15. Effects of chronic oral treatment with UK38,485 (100 mg/ $\mathrm{kg} \cdot \mathrm{d} \times 7 \mathrm{~d})$ on vascular responsiveness to AII in spontaneously hypertensive rats pretreated with indomethacin $(5 \mathrm{mg} / \mathrm{kg} \times$ three doses, subcutaneously).

vide the prerequisite arrangement of enzymes necessary for enabling endoperoxide shunting. However, if platelet-endothelial interactions were responsible for the endoperoxide shunting that attenuates responses to AII, then both acute and chronic administration of UK 38,485 should reduce the vascular response to AII. In contrast to this prediction, even though acute and chronic administration of UK 38,485 caused equivalent inhibition of platelet $\mathrm{TXA}_{2}$ synthase at the time vascular responsiveness was assessed, only chronic treatment attenuated the vascular response to AII. This result excludes platelet-endothelial interactions as the source of endoperoxide shunting responsible for attenuating vascular responses to AII. Instead, the novel concept that endoperoxide shunting may occur within the blood vessel is supported. Because time would be required for penetration of UK 38,485 into the blood vessel wall, this hypothesis would explain the observation that chronic, but not acute, administration of UK38,485 attenuates the vascular response to AII.

The effects of chronic administration of UK 38,485 on vascular responses to AII in both normotensive and hypertensive rats were investigated. $\mathrm{TXA}_{2}$ production may be elevated in the
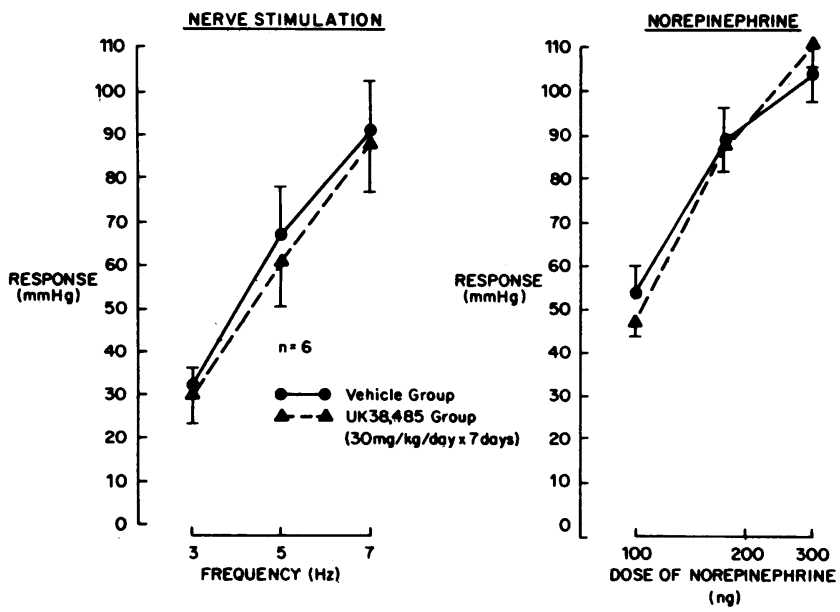

Figure 16. Effects of chronic oral treatment with UK38,485 (30 mg/ $\mathrm{kg} \cdot \mathrm{d} \times 7 \mathrm{~d}$ ) on vascular responses to PNS (left panel) and exogenous $\mathrm{NE}$ (right panel) in spontaneously hypertensive rats.
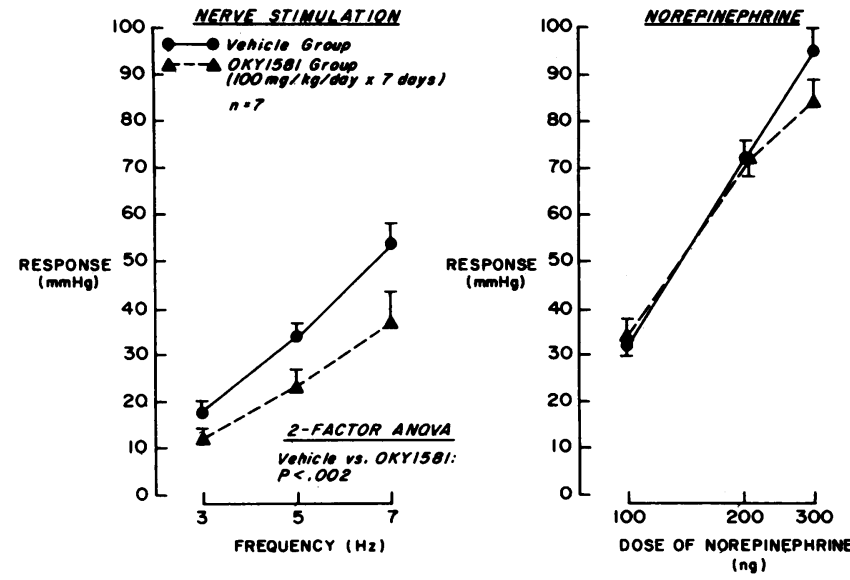

Figure 17. Effects of chronic oral treatment with OKY $1581(100 \mathrm{mg} /$ $\mathrm{kg} \cdot \mathrm{d} \times 7 \mathrm{~d}$ ) on vascular responses to PNS (left panel) and exogenous NE (right panel) in spontaneously hypertensive rats.

spontaneously hypertensive rat $(30,31)$ and, therefore, the effects of $\mathrm{TXA}_{2}$ synthase inhibitors may be more pronounced in this strain. However, UK 38,485 attenuated vascular responses similarly in both normotensive and hypertensive rats and, in both cases, the attenuation was blocked with indomethacin. Therefore, a greater role for $\mathrm{TXA}_{2}$ synthase activity in spontaneously hypertensive rats is not supported.

Chronic administration of UK38,485, OKY 1581, and U$63557 \mathrm{~A}$ also attenuated the vascular response to sympathetic nerve stimulation. Like the response to AII, the response to sympathetic nerve stimulation was not attenuated significantly by acute treatment with UK38,485. Further, chronic treatment with lower doses of UK 38,485 and U-63557A did not alter vascular responsiveness to sympathetic nerve stimulation, despite the fact that platelet $\mathrm{TXA}_{2}$ synthase activity was nearly abolished at the time vascular reactivity was assessed. Again, these data indicate that the relevant pool of $\mathrm{TXA}_{2}$ synthase does not lie within the platelet, rather the attenuation of vascular responsiveness to nerve stimulation by $\mathrm{TXA}_{2}$ synthase inhibition is due to inhibition of some less accessible pool of $\mathrm{TXA}_{2}$ synthase such as the blood vessel wall, or perhaps even the sympathetic neuroeffector junction.

The mechanism of attenuation of responses to sympathetic nerve stimulation by $\mathrm{TXA}_{2}$ synthase inhibition also appears to

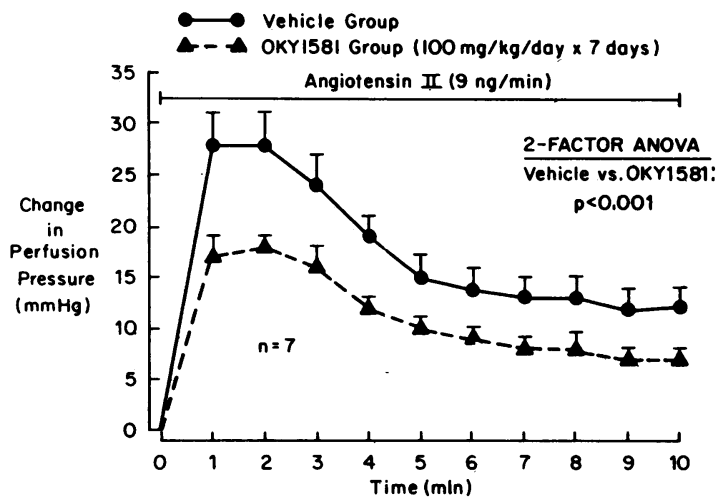

Figure 18. Effects of chronic oral treatment with OKY1581 (100 mg/ $\mathrm{kg} \cdot \mathrm{d} \times 7 \mathrm{~d}$ ) on vascular responsiveness to AII in spontaneously hypertensive rats. 

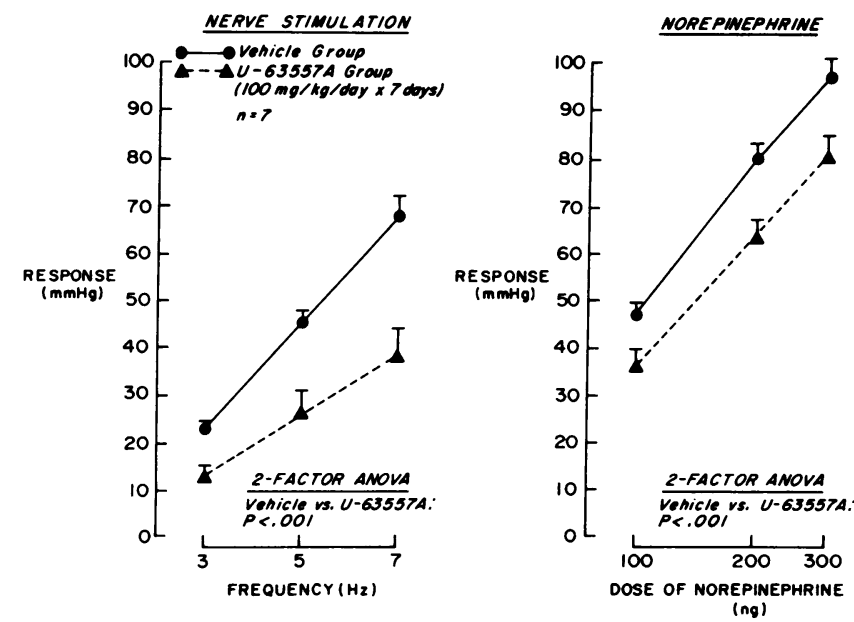

Figure 19. Effects of chronic oral treatment with U-63557A $(100 \mathrm{mg} /$ $\mathrm{kg} \cdot \mathrm{d} \times 7 \mathrm{~d}$ ) on vascular responses to PNS (left panel) and exogenous $\mathrm{NE}$ (right panel) in spontaneously hypertensive rats.

be due to endoperoxide shunting. Cyclooxygenase inhibition did not reduce the response to sympathetic nerve stimulation, yet in three separate studies cyclooxygenase inhibition prevented the attenuating effects of TXA $\mathrm{A}_{2}$ synthase inhibition on vascular responsiveness to sympathetic nerve stimulation. These observations are inconsistent with an exclusive role for $\mathrm{TXA}_{2}$, but are consistent with the hypothesis that endoperoxide shunting enhances prostaglandin biosynthesis and prostaglandins, either per se or in combination with the reduction in $\mathrm{TXA}_{2}$ levels, then attenuate the response to nerve stimulation.

Like attenuation of AII responses, the attenuation of responses to sympathetic nerve stimulation by $\mathrm{TXA}_{2}$ synthase inhibition was similar in normotensive and hypertensive rats. Again, these data do not support a greater role for $\mathrm{TXA}_{2}$ synthase in spontaneously hypertensive rats.

The results obtained in these studies clearly indicate that chronic inhibition of TXA $\mathrm{T}_{2}$ synthase attenuates the overall neurotransmission process, most likely via a prostaglandin-dependent mechanism. Prostaglandins can attenuate sympathetic neurotransmission by two basic mechanisms, i.e., by decreasing neurotransmitter release or by reducing the postjunctional responsiveness to NE (13-18). The first mechanism would alter the effector organ response to nerve activation, but would not modify the effector response to exogenously administered neu-

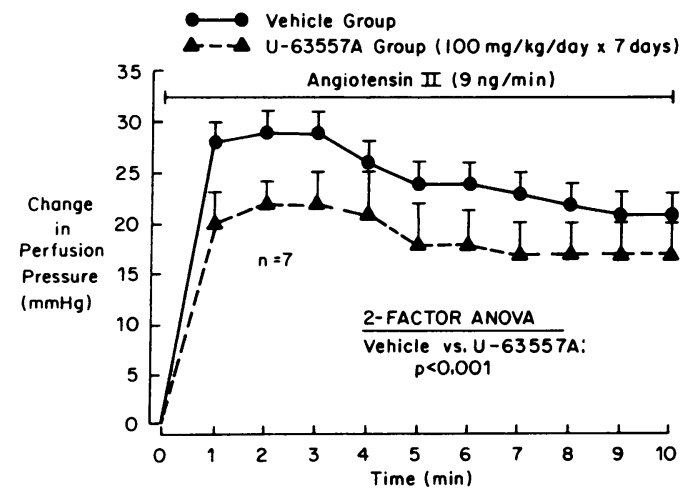

Figure 20. Effects of chronic oral treatment with U-63557A (100 mg/ $\mathrm{kg} \cdot \mathrm{d} \times 7 \mathrm{~d}$ ) on vascular responsiveness to AII in spontaneously hypertensive rats.

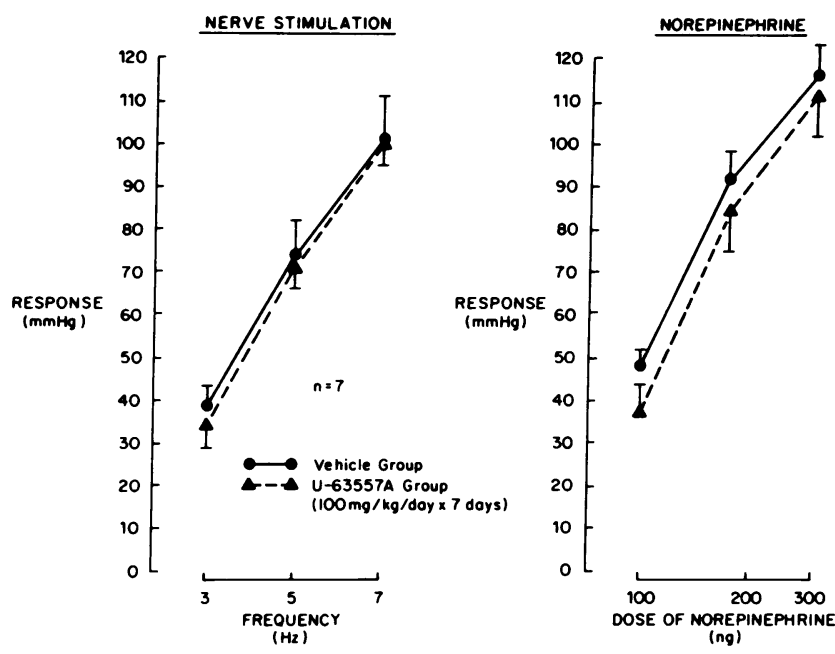

Figure 21. Effects of chronic oral treatment with U-63557A $(100 \mathrm{mg} /$ $\mathrm{kg} \cdot \mathrm{d} \times 7 \mathrm{~d}$ ) on vascular responses to PNS (left panel) and exogenous $\mathrm{NE}$ (right panel) in spontaneously hypertensive rats pretreated with indomethacin $(5 \mathrm{mg} / \mathrm{kg} \times$ three doses, subcutaneously).

rotransmitter. In contrast, a postjunctional change in the relationship between neurotransmitter concentration and end-organ response usually would alter the response to both nerve activation and exogenously applied neurotransmitter. Implicit in this latter statement is the assumption that receptor-effector coupling at sites activated by endogenous neurotransmitter is influenced similarly to coupling at receptor sites activated by exogenous neurotransmitter. Because chronic administration of UK38,485 and OKY 1581 reduced the vascular response to PNS, without altering the vascular response to exogenous norepinephrine, it appears that these two agents attenuate nerve stimulation-induced exocytosis, but do not alter postjunctional responsiveness to NE. On the other hand, chronic administration of U-63557A attenuated the vascular response to both PNS and exogenous $\mathrm{NE}$; however, the magnitude of the displacement of the frequency-response curve was greater than the displacement of the norepinephrine dose-response curve. Further, the attenuation of the vascular response to PNS by U-63557A was greater than that obtained with either UK38,485 or OKY 1581. These data are consistent with the hypothesis that U-63557A acts similarly

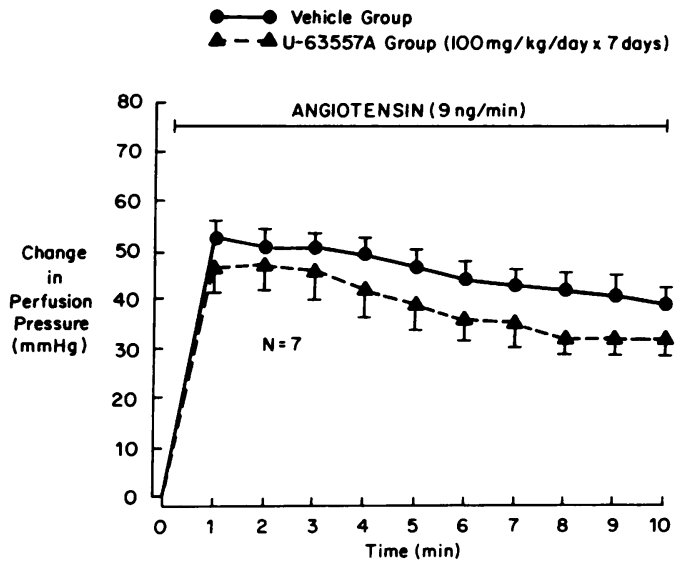

Figure 22. Effects of chronic oral treatment with U-63557A (100 mg/ $\mathrm{kg} \cdot \mathrm{d} \times 7 \mathrm{~d}$ ) on vascular responsiveness to AII in spontaneously hypertensive rats pretreated with indomethacin $(5 \mathrm{mg} / \mathrm{kg} \times$ three doses, subcutaneously). 

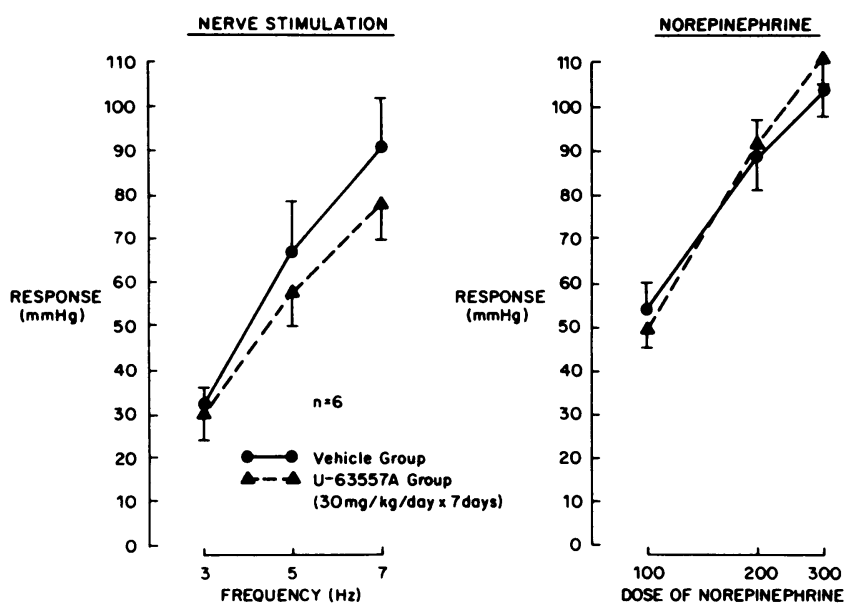

Figure 23. Effects of chronic oral treatment with U-63557A $(30 \mathrm{mg} /$ $\mathrm{kg} \cdot \mathrm{d} \times 7 \mathrm{~d}$ ) on vascular responses to PNS (left panel) and exogenous $\mathrm{NE}$ (right panel) in spontaneously hypertensive rats.

to UK38,485 and OKY 1581 to inhibit NE release, but in addition attenuates the postjunctional response to NE.

The effects of $\mathrm{TXA}_{2}$ synthase inhibition on exogenous NEinduced vascular responses are the most difficult to understand. Chronically, neither UK38,485 nor OKY 1581 altered the vascular response to exogenous NE. These observations indicate that chronic inhibition of $\mathrm{TXA}_{2}$ synthase does not attenuate the vascular response to exogenous norepinephrine. In contrast, chronic administration of U-63557A did significantly attenuate the vascular response to exogenous NE. A likely explanation for this discrepancy is that U-63557A exerts an action on NE responsiveness unrelated to $\mathrm{TXA}_{2}$ synthase inhibition. This would account for the fact that U-63557A reduces the vascular response to exogenous NE, whereas UK38,485 and OKY1581 do not, and for the fact that U-63557A exerts a greater influence on vascular responses to sympathetic nerve stimulation than do UK38,485 and OKY 1581 .

Another observation difficult to reconcile is that acute administration of UK 38,485 reduces vascular responsiveness to exogenous NE, but not significantly to PNS or AII, whereas chronic UK38,485 administration reduces vascular responsiveness to PNS and AII, but not to NE. However, both the acute and chronic effects of UK 38,485 are blocked by indomethacin. Although these observations require further investigation, a possible explanation is that administration of $\mathrm{TXA}_{2}$ synthase inhibitors, either acutely or chronically, causes endoperoxide shunting at the platelet-endothelial interface. This would increase prostaglandin levels primarily at the intimal side of the blood vessel, whereas NE released from sympathetic nerve terminals would affect primarily smooth muscle cells underlying the adventitia. Therefore, endoperoxide shunting owing to platelet-endothelial interactions would be expected to reduce vascular responses more to exogenously administered NE than to NE released by nerve terminals. This would explain the observation that acute administration of UK 38,485 attenuates the vascular response more to exogenous NE than to sympathetic nerve stimulation. It may be important to note that although acute administration of UK 38,485 did not significantly reduce vascular responses to sympathetic nerve stimulation, the responses tended to be suppressed and a larger sample size may have revealed a statistically significant result. As the treatment with UK 38,485 is extended, a tolerance may develop to the
Table II. Base-line Mesenteric Perfusion

Pressures and Mean Arterial Blood Pressures

\begin{tabular}{|c|c|c|c|}
\hline Protocol no. & Group & Perfusion pressure & $\begin{array}{l}\text { Mean arterial } \\
\text { blood pressure }\end{array}$ \\
\hline & & $m m H g$ & $m m H g$ \\
\hline \multirow[t]{2}{*}{1} & Experimental & $68 \pm 6$ & $119 \pm 4$ \\
\hline & Control & $78 \pm 9$ & $123 \pm 5$ \\
\hline \multirow[t]{2}{*}{2} & Experimental & $62 \pm 4$ & $98 \pm 2$ \\
\hline & Control & $56 \pm 5$ & $107 \pm 5$ \\
\hline \multirow[t]{2}{*}{3} & Experimental & $58 \pm 5$ & $106 \pm 6$ \\
\hline & Control & $57 \pm 3$ & $105 \pm 3$ \\
\hline \multirow[t]{2}{*}{4} & Experimental & $52 \pm 7$ & $90 \pm 6$ \\
\hline & Control & $55 \pm 2$ & $121 \pm 3$ \\
\hline \multirow[t]{2}{*}{5} & Experimental & $74 \pm 2$ & $109 \pm 6^{*}$ \\
\hline & Control & $78 \pm 5$ & $141 \pm 11$ \\
\hline \multirow[t]{2}{*}{6} & Experimental & $80 \pm 6$ & $125 \pm 6$ \\
\hline & Control & $83 \pm 2$ & $124 \pm 7$ \\
\hline \multirow[t]{2}{*}{7} & Experimental & $82 \pm 2$ & $153 \pm 6$ \\
\hline & Control & $87 \pm 2$ & $153 \pm 2$ \\
\hline \multirow[t]{2}{*}{8} & Experimental & $84 \pm 6$ & $143 \pm 2$ \\
\hline & Control & $84 \pm 3$ & $145 \pm 3$ \\
\hline \multirow[t]{2}{*}{9} & Experimental & $85 \pm 3$ & $133 \pm 6$ \\
\hline & Control & $94 \pm 5$ & $133 \pm 4$ \\
\hline \multirow[t]{2}{*}{10} & Experimental & $81 \pm 4$ & $126 \pm 4$ \\
\hline & Control & $85 \pm 3$ & $138 \pm 4$ \\
\hline \multirow{2}{*}{11} & Experimental & $85 \pm 4$ & $157 \pm 3$ \\
\hline & Control & $87 \pm 2$ & $153 \pm 2$ \\
\hline
\end{tabular}

Values indicate mean \pm SEM.

* $P<0.05$ (unpaired Student's $t$ test) compared to control. For details on what treatment each group received see Table $I$.

effects of prostaglandins on NE responsiveness, but not to the prejunctional actions of prostaglandins on neurotransmitter release. Therefore, vascular responsiveness to exogenous NE would return to normal, whereas vascular responses to sympathetic nerve stimulation would decrease as endoperoxide shunting within the blood vessel wall is established and inhibits neurotransmitter release. Like sympathetic nerve stimulation, the vascular reactivity to AII may be affected more by endoperoxide shunting within the blood vessel wall than by endoperoxide shunting due to platelet-endothelial interactions. Whatever the true explanation for the time-related effects of $\mathrm{TXA}_{2}$ synthase inhibitors, all future studies with these compounds should take into consideration the fact that the acute and chronic effects on vascular responsiveness are quite different.

In a previous short communication, I reported that chronic administration of UK 38,485 attenuates the vascular response to sympathetic nerve stimulation, but not to exogenous NE, in the normotensive rat (32). This observation was confirmed and extended in the present study. In the previous study, the effect of chronic UK 38,485 administration on the vascular response to AII also was examined and found not to be statistically significant. However, only the peak responses to AII were compared, rather than the response over a 10 -min infusion. When 
the latter approach is used the vascular response to AII is statistically significantly attenuated by chronic administration of UK38,485.

In conclusion, chronic administration of $\mathrm{TXA}_{2}$ synthase inhibitors attenuates vascular responses to AII and sympathetic nerve stimulation, but not usually to NE. These effects are blocked, but not mimicked, by cyclooxygenase inhibition. Further, the altered vascular responsiveness induced by $\mathrm{TXA}_{2}$ synthase inhibitors does not correlate with platelet $\mathrm{TXA}_{2}$ synthase activity. Taken together, my observations suggest that chronic $\mathrm{TXA}_{2}$ synthase inhibition reduces vascular responsiveness perhaps by causing endoperoxide shunting within the blood vessel wall.

\section{Acknowledgments}

This work was supported by a grant-in-aid from the American Heart Association with funds contributed in part by the Tennessee affiliate and by grant HL-35909 from the National Institutes of Health. Edwin K. Jackson is an Established Investigator of the American Heart Association.

\section{References}

1. Blumberg, A., S. Denny, K. Nishikawa, E. Pure, G. R. Marshall, and P. Needleman. 1976. Angiotensin III-induced prostaglandin (PG) release. Prostaglandins. 11:195-197.

2. Brown, A. C., R. M. Zusman, and E. Haber. 1980. Identification of an angiotensin receptor in rabbit renomedullary interstitial cells in tissue culture. Correlation with prostaglandin biosynthesis. Circ. Res. 46:802-807.

3. Schwartzman, M., E. Liberman, and A. Raz. 1981. Bradykinin and angiotensin II activation of arachidonic acid deacylation and prostaglandin $\mathrm{E}_{2}$ formation in rabbit kidney. Hormone-sensitive versus hormone-insensitive lipid pools of arachidonic acid. J. Biol. Chem. 256: 2329-2333.

4. Pipili, E., and N. L. Poyser. 1981. Effects of nerve stimulation and of administration of noradrenaline or potassium chloride upon the release of prostaglandins $I_{2}, E_{2}$ and $F_{2 \alpha}$ from the perfused mesenteric arterial bed of the rabbit. Br. J. Pharmacol. 72:89-93.

5. Desjardins-Giasson, S., J. Gutkowska, R. Garcia, and J. Genest. 1982. Effect of angiotensin II and norepinephrine on release of prostaglandins $\mathrm{E}_{2}$ and $\mathrm{I}_{2}$ by the perfused rat mesenteric artery. Prostaglandins. 24:105-114.

6. Hassid, A., and C. Williams. 1983. Vasoconstrictor-evoked prostaglandin synthesis in cultured vascular smooth muscle. Am. J. Physiol. 245:C278-C282.

7. Ardaillou, N., J. Hagege, M.-P. Nivez, R. Ardaillou, and D. Schlondorff. 1985. Vasoconstrictor-evoked prostaglandin synthesis in cultured human mesangial cells. Am. J. Physiol. 248:F240-F246.

8. Needleman, P., A. Wyche, and A. Raz. 1979. Platelet and blood vessel arachidonate metabolism and interaction. J. Clin. Invest. 63:345349.

9. FitzGerald, G. A., A. R. Brash, J. A. Oates, and A. K. Pedersen. 1983. Endogenous prostacyclin biosythesis and platelet function during selective inhibition of thromboxane synthase in man. J. Clin. Invest. 72: 1336-1343.

10. Blair, I. A., P. J. Lewis, M. A. Orchard, and K. A. Waddell. 1983. Prostanoid production by human platelet: Redirection by the thromboxane synthetase inhibitor UK37,248. Br. J. Pharmacol. 79:356P.

11. Maguire, E. D., and R. B. Wallis. 1983. In vivo redirection of prostaglandin endoperoxides into 6-keto-PGF ${ }_{1 \alpha}$ formation by thromboxane synthetase inhibitors in the rat. Thrombosis Res. 32:15-27.

12. Patrignani, P., P. Filabozzi, F. Catella, F. Pugliese, and C. Patrono. 1984. Differential effects of dazoxiben, a selective thromboxane-synthase inhibitor, on platelet and renal prostaglandin-endoperoxide metabolism. J. Pharmacol. Exp. Ther. 228:472-477.
13. Hedqvist, P. 1977. Basic mechanisms of prostaglandin action on autonomic neurotransmission. Annu. Rev. Pharmacol. Toxicol. 17:259279.

14. Hemker, D. P., and J. W. Aiken. 1980. Modulation of autonomic neurotransmission by $\mathrm{PGD}_{2}$ : Comparison with effects of other prostaglandins in anesthetized cats. Prostaglandins. 20:321-332.

15. Hemker, D. P., and J. W. Aiken. 1981. Actions of indomethacin and prostaglandins $E_{2}$ and $D_{2}$ on nerve transmission in the nictitating membrane of the cat. Prostaglandins. 22:599-611.

16. Weitzell, R., A. Steppeler, and K. Starke. 1978. Effects of prostaglandin $E_{2}$, prostaglandin $I_{2}$ and 6-keto-prostaglandin $F_{1 \alpha}$ on adrenergic neurotransmission in the pulmonary artery of the rabbit. Eur. J. Pharmacol. 52:137-141.

17. Wennmalm, A. 1978. Prostaglandin-mediated inhibition of noradrenaline release. $V$. A comparison of the neuroinhibitory effect of three prostaglandins: $\mathrm{E}_{2}, \mathrm{I}_{2}$ and 6-keto-PGF $\mathrm{F}_{1 \alpha}$. Prostaglandins Med. 1:49-54.

18. Hedqvist, P. 1979. Actions of prostacyclin $\left(\mathrm{PGI}_{2}\right)$ on adrenergic neuroeffector transmission in the rabbit kidney. Prostaglandins. 17:249258.

19. Timimi, K. S. A., J. R. Bedwani, and A. W. B. Stanton. 1978. Effects of prostaglandin $E_{2}$ and a prostaglandin endoperoxide analogue on neuroeffector transmission in the rat anococcygeus muscle. $\mathrm{Br}$. $J$. Pharmacol. 63:167-176.

20. Makita, Y. 1983. Effects of prostaglandin $I_{2}$ and carbocyclic thromboxane $A_{2}$ on smooth muscle cells and neuromuscular transmission in the guinea-pig mesenteric artery. Br. J. Pharmacol. 78:517-527.

21. Jackson, E. K., and W. B. Campbell. 1981. A possible antihypertensive mechanism of propranolol: antagonism of angiotensin II enhancement of sympathetic nerve transmission through prostaglandins. Hypertension (Dallas). 3:23-33.

22. Jackson, E. K., and W. B. Campbell. 1980. The in situ blood perfused rat mesentery; a model for assessing modulation of adrenergic neurotransmission. Eur. J. Pharmacol. 66:217-224.

23. Eikenburg, D. C. 1984. Functional characterization of the preand post-junctional $\alpha$-adrenoreceptors in the in situ perfused rat mesenteric vascular bed. Eur. J. Pharmacol. 105:161-165.

24. Uderman, H. D., R. J. Workman, and E. K. Jackson. 1982. Attenuation of the development of hypertension in spontaneously hypertensive rats by the thromboxane synthetase inhibitor, 4-(imidazol-1yl) acetophenone. Prostaglandins. 24:237-244.

25. Patrono, C., G. Ciabattoni, E. Pinca, F. Pugliese, G. Castrucci, A. DeSalvo, M. A. Satta, and B. A. Peskar. 1980. Low dose aspirin and inhibition of thromboxane $\mathbf{B}_{\mathbf{2}}$ production in healthy subjects. Thromb. Res. 17:317-327.

26. Viinikka, L., and O. Vlikorkala. 1980. Measurement of thromboxane $\mathrm{B}_{2}$ in human plasma or serum by radioimmunoassay. Prostaglandins. 20:759-766.

27. Patrignani, P., P. Filabozzi, and C. Patrono. 1982. Selective cumulative inhibition of platelet thromboxane production by low dose aspirin in healthy subjects. J. Clin. Invest. 69:1366-1372.

28. Cooper, C. L., J. E. Shaffer, and K. U. Malik. 1985. Mechanism of action of angiotensin II and bradykinin on prostaglandin synthesis and vascular tone in the isolated rat kidney. Effect of $\mathrm{Ca}^{++}$antagonists and calmodulin inhibitors. Circ. Res. 56:97-108.

29. Hamberg, M., J. Svensson, and B. Samuelsson. 1975. Thromboxanes: a new group of biologically active compounds derived from prostaglandin endoperoxides. Proc. Natl. Acad. Sci. USA. 72:2994-2998.

30. Shibouta, Y., Z.-I. Terashita, Y. Inada, K. Nishikawa, and S. Kikuchi. 1981. Enhanced thromboxane $A_{2}$ biosynthesis in the kidney of spontaneously hypertensive rats during development of hypertension. Eur. J. Pharmacol. 70:247-256.

31. Konieczkowski, M., M. J. Dunn, J. E. Stork, and A. Hassid. 1983. Glomerular synthesis of prostaglandins and thromboxane in spontaneously hypertensive rats. Hypertension (Dallas). 5:446-452.

32. Jackson, E. K., H. D. Uderman, W. A. Herzer, and R. A. Branch. 1984. Attenuation of noradrenergic neurotransmission by the thromboxane synthetase inhibitor, UK38,485. Life Sci. 35:221-228. 